\title{
A influência e Aplicação prática da qualidade de vida no trabalho como fator essencial na alavancagem da produção e crescimento empresarial brasileiro
}

The influence and practical application of Quality of Life at Work as an essential factor in leveraging production and brazilian business growth

La influencia y aplicación práctica de la Calidad de vida en el trabajo como factor esencial para apalancar la producción y el crecimiento empresarial brasileño

\begin{abstract}
Resumo
Objetivo desse trabalho é retratar A qualidade de vida no trabalho que é um conjunto de ações que as empresas brasileiras adotam, a influência e os impactos dentro do ambiente empresarial. A importância de coexistir em um ambiente favorável de trabalhofaz com que os funcionários produzem mais, por isso à busca pela qualidade de vida no trabalho tem sido um dos assuntos mais abordados pelas empresas, observa-se que manter seus funcionários num convívio social agradável, saudável está diretamente ligado a forma como o mesmo irá se dedicar nas suas tarefas diárias, produzindo muito mais em pouco tempo, o que é um fator potencial para o crescimento da empresa. Assim diante de um mercado competitivo às empresas precisam de açõesestratégicas necessárias para motivação e satisfação do pessoal e consequentemente aumento da produtividade. Percebe-se que a qualidade de vida no trabalho e produtividade estão associados diretamente com o bem-estar do trabalhador e com a eficácia organizacional, empresas diferenciadas e competitivas buscam incessantemente por qualidade em todas as áreas, sabendo que o capital humano é primordial, buscam investir em QVT. Nesse presente artigo iremos abordar à influência da QVT como um dos principais fatores para alavancagem na produtividade e crescimento Organizacional.
\end{abstract}

Palavras-chave: Qualidade de vida no trabalho; Motivação; Produtividade; Vantagem competitiva.

\begin{abstract}
The objective of this work is to portray the quality of life in the work that is a set of actions that the Brazilian companies adopt, the influence and the impacts within the business environment. The importance of coexisting in a favorable work environment makes the employees produce more, so the search for quality of life at work has been one of the subjects most addressed by companies, it is observed that keeping their employees in a pleasant social, healthy is directly connected to how the same will devote to their daily tasks, producing much more in a short time, which is a potential factor for the growth of the company. Thus, in the face of a competitive market, companies need the necessary strategic measures to motivate and satisfy the personnel and consequently increase productivity. It is perceived that the quality of life at work and productivity are directly associated with the well-being of the worker and with the organizational effectiveness, differentiated and competitive companies seek incessantly for quality in all areas, knowing that human capital is primordial, seek invest in QVT. In this article we will discuss the influence of QVT as one of the main factors forleverage in Organizational productivity and growth.
\end{abstract}

Keywords: Quality of life at work; Motivation; Productivity; Competitive advantage.

\section{Resumen}

El objetivo de este trabajo es retratar la calidad de vida en el trabajo que es un conjunto de acciones que adoptan las empresas brasileñas, la influencia y los impactos en el entorno empresarial. La importancia de convivir en un ambiente laboral favorable hace que los empleados produzcan más, por lo que la búsqueda de la calidad de vida en el trabajo ha sido uno de los temas más abordados por las empresas, se observa que mantener a sus empleados en un ambiente social agradable, saludable es directamente conectado a cómo los mismos se dedicarán a sus tareas diarias, produciendo mucho más en poco tiempo, lo cual es un factor potencial para el crecimiento de la empresa. Así, ante un mercado competitivo, las empresas necesitan las medidas estratégicas necesarias para motivar y satisfacer al personal y aumentar la productividad. Se percibe que la calidad de vida en el trabajo y la productividad están directamente asociados con el bienestar del trabajador y con la efectividad organizacional, empresas diferenciadas y competitivas buscan incesantemente la calidad en todos los ámbitos, sabiendo que el capital humano es primordial, invierten en 
QWL. En este artículo discutiremos la influencia de QVT como uno de los principales factores de apalancamiento en la productividad y el crecimiento organizacional.

Palabras clave: Calidad de vida en el trabajo; Motivación; Productividad; Ventaja competitiva.

\section{Introdução}

O avanço da tecnologia e a globalização acarretou muitas mudanças no mundo atual, em diferentes setores, o setor empresarial foi um dos setores que mais sofreu com os impactos dessa evolução. Devido ao cenário atual empresarial caracterizado por muitas mudanças percebe-se cada vez mais competitividade entre às empresas, busca por inovação, e diferenciabilidade são essenciais para se manter no mercado. Com isso, as empresas buscam novos métodos, para se mantere destacarem utilizando o conceito presente nesse artigo que é a Qualidade de vida no trabalho.

Com o passar dos anos, grandes evoluções aconteceram, diferentes ambientes de conhecimentos e novas metodologias se desvelam, trazendo comisso a necessidade de reformar os modelos já existentes, assim surgiu uma nova visão, em que os colaboradores fazem parte fundamental da estrutura ambiental empresarial e não retratado apenas como maquinas de produção, pois esses são os grandes responsáveis por todo processo, de coordenar, controlar, produzir e principalmente dos resultados. Com um cenário moderno distinto, às empresas começaram a olhar seus colaboradores como um capital valioso e potencial investimento. Investindo cada vez mais no capital humano, ocasionando um diferencial competitivo, alto retorno e crescimento. Desde 2001, segundo Tolfo e Piccinini, as organizações voltam seu interesse às pessoas, visto serem os colaboradores aqueles que, de modo geral, possibilitam a obtenção de maior vantagem competitiva, sendo necessária a implementação de ações que propiciem a Qualidade de Vida no Trabalho. Sabendo-se que o Capital Humano constitui força vital no alcance dos objetivos, a organização tem a necessidade de gerenciar e unificar as forças contribuintes promovendo a qualidade de vida no trabalho, fortalecendo o vínculo profissional e estimulação de equipes ao comprometimento e alcance de resultados. A dinâmica empreendida no contexto de qualidade de vida do trabalho não está apenas ligada ao clima organizacional, está ligada a satisfação pessoal e profissional do contribuinte, tendo observado que o profissional satisfeito e feliz produz mais e melhor.

Nessa linha, evidencia-se que da mesma forma em que o ambiente de trabalho interfere na vida e no bem-estar do colaborador, a sua conduta e as forças externas que o mesmo leva para o seu trabalho interfere no clima organizacional, com isso a qualidade de vida no trabalho está diretamente ligada a satisfação do colaborador e os resultados da empresa.

Os colaboradores passam cerca de horas dos seus dias no trabalho, onde relações, laços e aprendizagens são criados, dessa maneira é de grande valor, analisar, estudar modelos novos de organizações que visam trabalho e vida pessoal como elementos complementares, remodelando à empresa, a entender que qualidade no trabalho é primordial, saber lidar com diferentes tipos de colaboradores e entender que pessoas não são maquinas, e sim seres capazes de aprender, ensinar, desenvolver e crescer sendo um grande potencial evolutivo no ambiente organizacional.

Neste sentido, para que os colabores se tornem mais produtivos, motivadose satisfeitos se faz necessário entender o conceito de qualidade de vida no trabalho como administração de modelo que além do bem-estar dos colaboradores e capaz de compreender as diferentes dimensões que atribui à QVT. O alvo principal é conciliar o profissional e seus interesses e os da empresa assim, elevando a produtividade.

O crescimento da produtividade está diretamente ligado a qualidade de vida no trabalho, visto que o excesso de trabalho acaba fazendo com que o colaborador fique, cansado, tenso, estressado, podendo comprometer sua vida pessoal, e até mesmo acarretar danos a saúde e com isso a queda da sua produtividade na empresa. Contudo à busca por esse equilíbrio em que permita o profissional altamente produtivo mas sem deixar de ter um ambiente elaborativo propicio à sua satisfaçãoe crescimento profissional, gerir um sistema de recompensas, motivações, jornadas de trabalho adequadas, remuneração 
adequada e dentre outros fatores com os objetivos da empresa e produtividade, vem sendo um grande desafio no atual cenário brasileiro.

Podemos observar que as quedas na produtividade se dá por um gerenciamentos de recursos e capital inadequados e muitos outros fatores e um dos principais é QVT, porém muitas empresas erram por acharem que o principal recursos são os matérias, visto casos e estudos, temos como principal capital o ser humano, entendendo esse conceito e aplicando-os, o investimento em funcionários irá obter um diferencial e consequentemente resultados rápidos e aumento na produtividade. Conforme foi exposto, propõem o seguinte questionamento para à pesquisa: Qual a influência e os impactos que a qualidade

\section{de vida no trabalho tem sobre a produtividade e crescimento empresarial dentro das empresas?}

Esse artigo tem como objetivo geral analisar e identificar a influência e os impactos que a qualidade de vida no trabalho tem sobre a produtividade e crescimento empresarial dentro das empresas.

Os objetivos específicos são:

Analisar a Qualidade de vida no Trabalho como fator essencial para o crescimento empresarial;

Analisar à Motivação ligada a QVT dos funcionários;

Identificar a influência que a QVT tem sobre a Produtividade e os impactos gerados e com isso a Vantagem competitiva.

A justificativa para elaboração desse trabalho, é a visão do homem como principal fator para o crescimento empresarial, visto que, as empresas estão em um mundo de constantes mudanças e evoluções, às organizações precisam adotar modelos de negócios para se manter no mercado e gerenciar da melhor forma seus recursos, sabendo que e um desse modelo é o presente nesse artigo, A qualidadede vida no trabalho traz uma visão mais ampla e estratégica. Contudo muitas empresas ainda não entendem e não aplicam esse gerenciamento de capital humano, assim fazendo muitas vezes dos seus funcionários máquinas, descartando o conceito citado nesse artigo.

Segundo Rodrigues (1994), a qualidade de vida no trabalho surgiu na década de 50, na Inglaterra, quando Eric Trist e seus colaboradores estudavam um modelo macro para agrupar o trinômio indivíduo/trabalho/organização. Assim surgiu esse termo Qualidade de vida no trabalho.

De acordo Limongi-França (1996), Qualidade de vida no trabalho é o conjunto das ações de uma empresa no sentido de implantar melhorias e inovações gerenciais, tecnológicas e estruturais no ambiente de trabalho. Podemos observar a qualidade de vida está liga uma série de fatores interligados, necessários para se alcançar objetivos estabelecidos no meio empresarial. Segundo Huse e Cummings (1985, p.15) a evolução no conceito de Qualidade de Vida no Trabalho passou a ser percebida à medida que pesquisas e intervenções nas organizações eram realizadas. Ao longo do tempo o conceito sobre qualidade de vida no trabalho era a percepção individual da pessoa em relação ao trabalho, assim particularmente focada em resultados individuais. Ainda em concordância com os mesmos autores, com avanço do conhecimento acerca do tema, ao passar dos anos a QVT passou a ser uma abordagem, técnicas utilizadas na reformulação do trabalho, passou a ser uma ideologia, um movimento em função dos direitos sociais.

Para De Marchi (1998 apud França, 2004) um dos fundadores e ex-presidente da Associação Brasileira de Qualidade de Vida entre os anos de 1998 a 1999 descreve a qualidade de vida das pessoas no âmbito pessoal e organizacional.

Qualidade de vida é estar saudável, desde a saúde física, cultural, espiritual até a saúde profissional, intelectual e social. Cada vez mais as empresas que desejarem estar entre as melhores do mercado deverão investir nas pessoas. Portanto, qualidade de vida é um fator de excelência pessoal e organizacional. (De MARCHI apud FRANÇA, 2004, p. 41). O fenômeno da globalização proporcionou a ampliação dos do contexto de QVT, entendo que a QVT além de estar ligado ao bem-estar, 
cultural, físico, mentala saúde do profissional, podemos enfatizar essa ligação diretamente ao crescimento empresarial, faz se potência para as empresas territorial objetivando ampliar sua competitividade no mercado mundial.

De acordo com Chiavenato (2004) a QVT envolve alguns fatores como: satisfação com o trabalho; a possibilidade de crescimento organizacional; o reconhecimento pelos resultados; salário; benefícios; relacionamento; ambiente de trabalho; poder de decisões; participação.

O colaborar em ambiente de trabalho em que se sinta satisfeito, onde há possibilidades de crescimento, reconhecimento pelos resultados, dentre outros fatores tende a render mais nas suas tarefas diárias, crescendo então a produtividade.

Vieira (1996) afirma que os principais fatores determinantes de QVT são: o próprio trabalho, as relações interpessoais, a política de recursos humanos e a empresa apresentada em cinco categorias.

$\mathrm{O}$ trabalho e qualidade de vida estão interligados tanto no âmbito profissional e empresarial. Atualmente algumas empresas entendem esse conceito e aplicam elevando cada vez mais o grau de produtividade e sucesso organizacional por meio de seus funcionários, porém ainda hoje muitas não aplicam e acabam não dando tanta importância para o assunto abordado neste artigo. Produtividade é a relação entre os meios, recursos utilizados e a produção final, é aproveitar da melhor maneira os recursos disponíveis, de forma que os resultados venham ser alcançados e competitivos. São vários os motivos que levam o aumento da produtividade, e um deles está associado a QVT.

Atualmente as empresas tem certa dificuldade para manter o alto índice de produtividades, num ambiente corporativo cada mais exigente e competitivo, utilizando de estratégias e meio para de manter no mercado. Existem diversosdesafios para uma organização elevar sua produtividade um deles é a ligação com profissionais da própria empresa

Segundo França (2004) o desafio é reconstruir, com bem-estar, o ambiente competitivo, altamente tecnológico, de alta produtividade do trabalho, e garantir ritmos e situações ecologicamente corretas. O bem-estar do profissional faz parte da QVT que influencia altamente na produtividade, nas diferentes dimensões, o bem-estar não é somente manter um ambiente saudável ao profissional, mas sim do bem-estar do mesmo sendo pessoa integra, cidadão e profissional. Profissionais capacitados e qualificados agregam valor para a empresa, contudo é relevante os investimentos nesses profissionais, entendendo que profissionais precisam ter atenção não apenas cobrança. Uma condução direcionada a melhoria da QVT gera grande resultados,Segundo Fernandes (1996)," a qualidade é antes de tudo uma questão de atitude. Quem faz e garante a qualidade são as pessoas, muito mais do que o sistema, as ferramentas e os métodos de trabalho". No Quadro 1 apresentam-se, alguns conceitos de forma sintética dosprincipais estudiosos do assunto Qualidade de Vida no Trabalho.

Quadro 1 - Conceitos sobre Qualidade de Vida do Trabalhador.

\begin{tabular}{|l|l|}
\hline Autores & Conceitos de qualidade de vida no trabalho \\
\hline Walton (1973) & $\begin{array}{l}\text { Designa preocupação com o resgate de valores humanísticos e ambientais, que vêmsendo } \\
\text { negligenciados em favor do avanço tecnológico, da produtividade e do crescimento econômico. }\end{array}$ \\
\hline Werther \& Davis(1983) & $\begin{array}{l}\text { São os esforços para melhorar a qualidade de vida procuram tornar os cargos mais produtivose } \\
\text { satisfatórios. }\end{array}$ \\
\hline Nadler \& Lawler(1983) & É vista como uma maneira de pensar a respeito das pessoas, do trabalho e dasorganizações. \\
\hline Fernandes (1996) & $\begin{array}{l}\text { A gestão dinâmica e contingencial de fatores físicos, tecnológicos e sócio psicológicos que afetam } \\
\text { a cultura e renovam o climaorganizacional, refletindo- se no bem-estar do trabalho e na } \\
\text { produtividade das empresas. }\end{array}$ \\
\hline Bom Sucesso(1998) & $\begin{array}{l}\text { Termo utilizado para avaliar as condições de vida urbana, incluindo transporte, saneamentobásico, } \\
\text { lazer a segurança, emoções e sentimentos das pessoas etc. }\end{array}$ \\
\hline
\end{tabular}


Conforme os conceitos acima podemos entender que essencial o conhecimento e aplicação da QVT, comoabordagem sistemática no meio organizacional, pois com a QVT, pode ser percebido muitos fatores positivos tanto pra o homem quanto para a organização à qual o mesmo presta serviços. De acordo com o autor Maximiano (1995, p. 318), "motivação, é o conjunto de razões ou motivos que explicam, induzem, incentivam ou provocam algum tipo deação de comportamento".

O ser humano pela psicologia ele tem um comportamento gerado conforme seu ambiente, seu cenário, ou seja, manter um ambiente favorável, onde se mantem vínculos positivos entre os profissionais, onde o mesmo pode se sentir satisfeito, estimula a motivação.

Segundo Davis e Newstron (1991, p, 47), "embora não haja respostas simples para a questão da motivação um importante ponto de partida reside na compreensão das necessidades do empregado".

É preciso compreender e relacionada as necessidades dos colaboradores, relacionadas metas e objetivos da empresa junto com a QVT, pois funcionários motivados geram grandes resultados para empresa.

Observa-se que a QVT e Motivação estão diretamente relacionados com a produtividade da empresa, funcionários motivos produzem mais, as empresas precisam entender esse conceito e aplica-lo, de forma que os funcionários tenham responsabilidades e perspectiva positiva no ambiente de trabalho.

$\mathrm{Na}$ atualidade o emprego da QVT ainda é um questionamento dentro do ambiente empresarial, empregar o conceito de QVT, vai muito além dos recursos materiais. Segundo Weiss, (1991, p, 32) “As pessoas trabalham por recompensas. Essas não precisam ser tangíveis, como dinheiro. Pode ser intangíveis, como no caso de deixar um funcionário ser líder de um grupo".

Partindo dessa perspectiva é de responsabilidade da empresa motivar seus funcionários, com treinamentos, oportunidade de carreira e recompensas, comoexigir do mesmo a responsabilidade com suas tarefas, porém essa perspectiva vem sendo muito diferente, pois cada vez mais as empresas exigem dos seus funcionários altos comprometimentos, e não dão o suporte necessários como treinamento, o que podemos observar são colaboradores desmotivados, doentes, muitas vezes pela a má administração e a falta da QVT que gera a desmotivação.

De acordo com Matos (1997), os fatores que influenciam decisivamente sobre a motivação humana são: trabalho em grupo, reconhecimento, segurança e integração ao grupo, necessidades fisiológicas, necessidade de segurança material, necessidades sociais, necessidade do ego, necessidade de autorrealização.

"A motivação, portanto, nasce somente das necessidades humanas e não daquelas coisas que satisfazem estas necessidades (Bergamini, 1997, p. 25)."

A motivação é primordial para alcançar os objetivos estabelecidos pela organização, pois colaboradores desmotivados não alcançam metas.

Equilibrar a motivação com os objetivos organizacionais é de tamanha importância, é essencial compreender as necessidades dos colaborados, questionamentos para se chegar ao resultado esperado, tendo em seu pleno conhecimento que que as pessoas, os funcionários, são as peças fundamentais parase chegar ao topo.

A ciência administrativa pode relatar que as teorias motivacionais geraram um resultado positivo para o trabalhador e sua produtividade, e as empresas passou a tratar esse assunto com mais importância e criaram programas relacionados a QVT Para Bateman e Shell (2006, p. 443), "estes programas foram projetados para criar um ambiente de trabalho que aumente o bem-estar dos funcionários e satisfazer à ampla gama de suas necessidades”. 


\section{Metodologia}

Em relação a abordagem do problema, o presente Estudo é de caráter exploratório qualitativo, existe uma relação entre os fatos analisados e os sujeitos - empresas brasileiras, mas estas relações não são traduzidas em números (Gil,2007).

De acordo com os objetivos desse artigo, a Pesquisa é descritiva, porque busca descrever as características da implementação da qualidade de vida no trabalho e dos fatores que influenciam na alavancagem da produtividade e crescimento empresarial das empresas brasileiras. De acordo com Ribeiro e Cruz (2004), a pesquisa descritiva tem por objetivo estudar, analisar, registar e interpretar os fatos do mundo físico sem a interferência do pesquisador. De acordo com o procedimento da pesquisa, foram utilizadas fontes bibliográficas variadas, como livros, artigos publicados na internet, dentre outros. Oliveira (2000) ressalta que a pesquisa bibliográfica acaba se transformando em rotina para os pesquisadores e profissionais que necessitam de constante atualização. Os métodos de pesquisa buscam comparar as particularidades das pessoas, em busca de comparações e análise dos dados, como diferenças e semelhanças entre culturas (americana e japonesa, por exemplo) ou padrões de comportamento (Vergara, 2009)

No presente artigo utilizou-se método dedutivo, onde parte-se das leis e teorias. Dessa maneira, observa-se o comportamento das empresas brasileiras diante do atual cenário brasileiro comercial, onde muitas, tem a dificuldade de investir na qualidade de vida no trabalho pois ainda não possuem o conhecimento e pratica do determinado assunto.

Pode se ter como estratégia a abordagem da QVT, manter seusfuncionários qualificados, predispostos, motivador, consequentemente o mesmo irá contribuir na melhor forma para a alavancagem da produção e crescimento organizacional. As empresas brasileiras são as principais observadas no presente artigo, visto que precisam utilizar de métodos e estratégias para se manter nomercado altamente competitivo. A pesquisa pode ainda ser compreendida em função do tempo de coleta.

\section{Resultados e Discussão}

Segunda Davis Newstron (1992, p. 28) "o resultado de um sistema eficaz de comportamento organizacional é a motivação que quando combinada com as habilidades e capacidades do empregado, resulta na produtividade humana"

As práticas e valores emergentes nas organizações relacionadas às questões de QVT são bastante diversificados, compreender e aplicar a QVTt é primordial para o crescimento como um todo, principalmente na produtividade.

Todos os pontos observados durante a pesquisa, a influência é visível, que QVT tem sobre a produtividade, muitas são as quedas na produção, devido aos funcionários não qualificados, desmotivados, estressados. É preciso aplicar e entender a QVT como forma de estratégia para empresa. Podemos observar como aplicação da QVT tem vantagem tanto para o funcionário quanto para à empresa. O trabalho ocupa muito tempo das pessoas, o que inicialmente era apenas suprimento das necessidades de sobrevivência, na atualidade se discuti muito acerca da qualidade de vida no trabalho, pois o homem ainda passa a maior parte dos seus dias no trabalho.

A Qualidade de vida no trabalho é um termo muito complexo desde da existência Humana já se tinha certa preocupação do Homem emrelação a esse assunto, embora, fosse um contexto de pouco conhecimento, com passar dos anos e conforme a globalização esse tema se tornou mais atraente tanto para os profissionais mais ainda nos meios empresariais.

Atualmente com aplicação da QVT os colaboradores são mais motivados, são mais instruídos, aceitando mais autoridade com menor probabilidade de questionamentos. E essa relação traz grande ganho para a organização, empresas com alto padrão, sendo reconhecidas pelos funcionários e clientes como empresa modelo, tendo alto crescimento na produtividade e consequentemente mantendo cada vez mais o crescimento empresarial. 


\section{Conclusão}

Conclui- se que é necessario a prática e abordagem do tema desse artigo para o futuro empresarial, apesar das constantes mudanças ocorridas dia a pós dia no ambiente corporativo, às empresas que procuram ter uma gestão ampliada e otiminizada dos Recursos Humanos, uma de presente: o que precisa melhorar no agora e futuro, suas metas a serem alcançadas, consegue se manter diante dessas mudanças constantes. Compreender os diversos fatores para se posicionar favoravelmente no mercado atual brasileiro é primordial para organização, utilizar de modelos, métodos e estratégias competitivas é um dos fatores que faz parte do dia-dia das empresas, as empresas precisam de mais investimentos em capital humano, visualiazar o potencial de Recursos humanos e corrigir erros relacionados a tal fator. A Qualidade de vida no trabalho era um assunto pouco abordado, porém ao passar dos anos pode se observar a grande influência que tem frente a organização empresarial, visto que abordagem desse tema se tornou cada vez mais realista entre às empresas tornando- as cada vez diferenciadas diante das demais, muitas captaram esse sistema e aplicou investimentos em QVT obtendo um retornou positivo.

No início deste trabalho o objetivo proposto era analisar os fatores que influenciam na alavancagem da produtividade e crescimento empresarial, como fator essencial e estratégico abordamos a Qualidade de vida no trabalho das empresas brasileiras no atual cenário.

A Qualidade de vida no trabalho era um assunto pouco abordado, porém ao passar dos anos pode se observar a grande influência que tem frente a organização empresarial, visto que abordagem desse tema se tornou cada vez mais realista entreàs empresas tornando-as cada vez diferenciadas diante das demais.

Quadro 2 - Evolução do conceito de QVT.

\begin{tabular}{|c|c|}
\hline Concepçầo evolutiva da QVT & Características ou visầo \\
\hline 1. QVT como uma variável (1959 a 1972) & $\begin{array}{l}\text { Reaçầo do individuo ao trabalho. Investigava-se como } \\
\text { melhorar a qualidade de vida no trabalho para o } \\
\text { individuo. }\end{array}$ \\
\hline 2. QVT como uma abordagem (1969 a 1974) & $\begin{array}{l}\text { O foco era o individuo antes do resultado organizacional; } \\
\text { mas, ao mesmo tempo, buscava-se trazer melhorias } \\
\text { tanto ao empregado como à direção. }\end{array}$ \\
\hline 3. QVT como um método (1972 a 1975) & $\begin{array}{l}\text { Um conjunto de abordagens, método ou técnicas para } \\
\text { melhorar o ambiente de trabalho e tornar o trabalho } \\
\text { mais produtivo e mais satisfatório. QVT era vista como } \\
\text { sinônimo de grupos autônomos de trabalho, } \\
\text { enriquecimento de cargo ou desenho de novas plantas } \\
\text { com integração social e técnica. }\end{array}$ \\
\hline 4. QVT como um movimento (1975 a 1980) & $\begin{array}{l}\text { Declaraçẫo ideológica sobre a natureza do trabalho e as } \\
\text { relações dos trabalhadores com a organizaçẫo. Os } \\
\text { termos "administração participativa" e "democracia } \\
\text { industrial" eram freqüentemente ditos como ideais do } \\
\text { movimento de QVT. }\end{array}$ \\
\hline 5. QVT como tudo (1979 a 1982) & $\begin{array}{l}\text { Como panacéia contra a competiçẫo estrangeira, } \\
\text { problemas de qualidade, baixas taxas de produtividade, } \\
\text { problemas de queixas e outros organizacionais. }\end{array}$ \\
\hline 6. QVT como nada (futuro) & $\begin{array}{l}\text { No caso de alguns projetos de QVT fracassarem no } \\
\text { futuro, não passará de um "modismo" passageiro. }\end{array}$ \\
\hline
\end{tabular}

Fonte: Nadler e Lawler apud Fernandes (1996).

Como Percebemos o Conceito da Qualidade de vida no trabalho vem evoluindo e ampliando a cada ano, conforme o quadro acima, percebemos as diferenças e sua concepção evolutiva, hoje se percebe a necessidade de pensar no futuro de uma forma a elevar as taxas de produtividade, resolver os problemas internos e externos da organiação, visualizar o entorno estratégico não só nacional mas também internacional de modo a ampliar a capacidade competitiva e produtiva, fazendo do hoje uma instituição pronta para o futuro e principalmente visando o capital humano como fator de alavancagem empresarial. 
Research, Society and Development, v. 10, n. 8, e55210817825, 2021

(CC BY 4.0) | ISSN 2525-3409 | DOI: http://dx.doi.org/10.33448/rsd-v10i8.17825

\section{Referências}

Bateman, T. S. \& Sneell, S. A. (2006). Administração: novo cenário competitivo. (2a ed.), Atlas.

Barros, M. A. (2017). Qualidade de vida no trabalho (QVT): a percepção de docentes de uma instituição de ensino superior privada. Revista Espaço Acadêmico.

Bergamini, C. W \& Coda, R. (1997). Psicodinâmica da vida organizacional: Motivaçãoe liderança. (2a ed.), Atlas.

Chiavenato, I. (2004). Gestão de pessoas: e o novo papel dos recursos humanos nas organizações. Elsevier.

Davis, K. N. \& John, W. (1992). Comportamento humano no trabalho: Uma abordagem psicológica. Pioneira Thomson Learning.

Davis, K. N. \& John, W. (2004). Comportamento humano no trabalho: uma abordagem organizacional. Pioneira Thomson Learning.

França, L. \& Ana, C. (2004). Qualidade de vida no trabalho - conceitos e práticas nas empresas da sociedade Pós-industrial. ed. Atlas.

Fernandes, E. C. (1996). Qualidade de Vida no Trabalho: como medir para melhorar. (2a ed.), Casa da Qualidade.

Gil, A.C. (1994). Métodos e técnicas de pesquisa social. (4a ed.), Atlas.

Limongi, F. \& A. C. (1996). Indicadores empresariais de qualidade de vida no trabalho: esforço empresarial e satisfação dos empregados no ambiente de manufatura com certificação IS 9000. FEA USP. Tese de doutorado.

Matos, F. G. (1997). Fator QF: Ciclo de felicidade no trabalho. Markron Books.

Maximiano, A. C. A. (1995). Introdução à administração. (4a ed.), Atlas.

Nespeca, M. C. \& Denise, C. (2011). Qualidade de vida no trabalho de funcionários públicos: papel da nutrição e da qualidade de vida. Acta Scientiarum. Health Science, 33, 187-195.

Ribeiro, U. \& Cruz, C. (2004). Metodologia Científica: teoria e prática. (2a ed.), Axcel Books.

Rodrigues, M. V. C. (1994). Qualidade de vida no trabalho: evolução eanálise no nível gerencial. (7a ed.), Vozes.

Seidl, E. M. F., Zannon \& Célia, M. L. C. (2004). Qualidade de vida e saúde: aspectos conceituais e metodológicos. Cadernos de Saúde Pública.

Vergara, S. C. (2009) Projetos e relatórios de pesquisa em administração. (10a ed.), Atlas

Vieira, A. (1996) A qualidade de vida no trabalho e o controle da qualidade total. Insular.

Walton, R. E. (1973). Qualidade de Vida no Trabalho: O que é isto? Atlas.

Weiss, D. (1991). Motivação e resultado - Como obter o melhor de sua equipe. Nobel.

Werther, B. W. \& Davis, K. (1983). Administração de pessoal e recursos humanos. McGraw-Hill. 